This is an electronic reprint of the original article. This reprint may differ from the original in pagination and typographic detail.

Author(s): Mustola, Marleena; Koivula, Merja; Turja, Leena; Laakso, Marja-Leena

Title: Reconsidering passivity and activity in children's digital play

Year: $\quad 2018$

Version:

Please cite the original version:

Mustola, M., Koivula, M., Turja, L., \& Laakso, M.-L. (2018). Reconsidering passivity and activity in children's digital play. New Media and Society, 20(1), 237-254. https://doi.org/10.1177/1461444816661550

All material supplied via JYX is protected by copyright and other intellectual property rights, and duplication or sale of all or part of any of the repository collections is not permitted, except that material may be duplicated by you for your research use or educational purposes in electronic or print form. You must obtain permission for any other use. Electronic or print copies may not be offered, whether for sale or otherwise to anyone who is not an authorised user. 


\title{
Reconsidering passivity and activity in children's digital play
}

\author{
Marleena Mustola, Merja Koivula, \\ Leena Turja and Marja-Leena Laakso \\ University of Jyväskylä, Finland
}

\begin{abstract}
The discussion around children's digital game culture has resulted in two contradictory images of children: the passive, antisocial children uncritically and mechanically consuming digital game content and the active, social children creatively using and interacting with digital game content. Our aim is to examine how these seemingly contradictory ideas of "active" and "passive" children could be considered. By means of empirical examples of children playing digital dress-up and makeover games, we will point out that for the successful use of these concepts, they need to be thoroughly contextualized. By discussing the context and referent of activity and passivity, it is possible to overcome the unnecessary polarization of the discourses on children's digital game culture. If the purpose is to advance the multidisciplinary discussion on digital games and childhood, the naive or careless use of the concepts of activity and passivity should be avoided.
\end{abstract}

\section{Keywords}

Activity, childhood, digital play, discourse, passivity

\section{Introduction}

Digital culture has become an essential part of children's contemporary culture, and at the same time, children's play with technologies has turned out to be a contested activity. Researchers have debated whether technologies enhance or inhibit children's development and learning (Stephen and Plowman, 2014: 331-332). Some see technology as an active component of children's play and learning (Jenkins, 2006; McClure and Sweeny, 2015), but others conceive of digital technology as supporting and causing passivity, thus preventing children from engaging in developmentally rich play and social activities (Blum and Parette, 2015: 166; Stephen and Plowman, 2014). There seems to be a debate about whether playing digital games should be considered "active" or "passive" activity. In this article, we seek to critically examine the concepts of "passivity" and

Corresponding author:

Marleena Mustola, Department of Education, University of Jyväskylä, PO Box 35, FI-40014

Jyväskylä, Finland.

Email: marleena.mustola@jyu.fi 
"activity," and we consider the limitations, challenges, and opportunities embedded in these concepts when used in the context of children's digital play.

The discourse on the passive reception of media is ongoing: concerned parents, educators, and politicians complain about a lack of physical activity or social interaction in children's digital play (e.g. Hadley and Nenga, 2004: 515; Stephen and Plowman, 2014: 332), and some researchers share concerns of passivity caused by an increased use of technology already at a very young age. These concerns typically focus on three main areas of negative impact: health and well-being (e.g. causing physical inactivity and passivity), cognition and brain development (e.g. the developmental inappropriateness of digital games), and social and cultural competencies (e.g. lack of communicational and social development, lack of adult company) (Stephen and Plowman, 2014: 331). Media discourses of child computer users "generally construct children as dependent and passive" (Shaw and Tan, 2015: 12). Especially in current discussions about the dangers of excess screen time, digital media is sometimes thought of as being "cold, inert, inactive, and devoid of life" (McClure and Sweeny, 2015: 252). Besides the narrative of digital games causing passivity, there exists moral panic about digital games leading to disturbing activity, such as violence; in this case, digital players are positioned as active participants in violent events (Marsh and Millard, 2000: 123).

On the other hand, there is also a strong discourse about children's positive activity in digital play culture. Many scholars have already suggested that children's interaction with digital media can be seen as a form of play rather than in terms of the moral panic and discourse of passivity (Jenkins, 2006; McClure and Sweeny, 2015), as acts of creative interpretation and negotiation (Behrenshausen, 2012), as production of meaning and pleasure (Buckingham and Sefton-Green, 2003), or as an exploration and resistance of dominant values as children act as social agents in their daily lifeworld (Hadley and Nenga, 2004; Marsh and Richards, 2013: 8). For decades, there have been debates on the active audience which shifted the emphasis from what the media do for people to what people do with media (Ross and Nightingale, 2003: 31). The role of an audience that coconstructs the content of media through various acts (Behrenshausen, 2012: 873; Livingstone, 2003; Mosca, 2014: 625) has been central within media and culture studies since 1990s, and the image of an active child can be located within that discourse.

If passivity and activity were to be discussed in the context of comparisons between different media, the results would be complex. The moral panic around digital gameplay (see Stephen and Plowman, 2014) suggests that as a medium it is more passive than reading, for instance. On the other hand, games can also be seen as an active medium because games let players use their (fictional) bodies when "a passive medium such as cinema dissociates the body and the mind” (Mosca, 2014: 624).

Certainly, there are variations between discourses belonging to the same or different disciplines. Within culture studies and childhood studies, children are usually seen as active citizens who create and recreate their own culture (Mayall, 2013). Within education and psychology, there are perspectives of children as both active users of digital culture and vulnerable, passive recipients of the culture produced for them (Livingstone, 2003; Stephen and Plowman, 2014), and the role of adult as protector and enabler is central. Within game studies, there exist two-sometimes contradictory-discourses: one that focuses on the active player and another that is interested in the agency of a game (Behrenshausen, 2012: 873). This (inter)disciplinary conversation about children and digital games culture constitutes a strange opposition between an active child and a passive child; on one hand, this is a 
new presentation of children and digital games culture, but, on the other hand, when considering the history of childhood, it is an old contradictory conception.

Childhood is a social construction (see Alanen, 2015), and the idea of a child-as well as the concept of childhood-has varied in past decades and centuries. Instead of debating the development of a distinct period of childhood separated from the adult world, historians have started to focus on the complex construction of childhood, which is heterogeneous in any given period (Rhodes, 2002: 166-167). One of the central constructions of "child" is that children are innocent and in need of protection (Mills, 2002: 10-11) which leads to giving less attention to children's own active involvement and power and implying that children are somewhat passive creatures. Neil Postman (1994 [1982]) claimed already in 1982 that as television became a dominant source of information, revealing adult realities and secrets to children, childhood started to disappear. There have been (and still are) many debates about the possibility that various media of popular culture are a threat to children's innocence and to children's lifeworld (Marsh and Millard, 2000: 102, 140). Modern construction of "child" emphasizes children's activity and sees children as persons in their own right (Mills, 2002: 21) and with their own rights, for example, right to play (United Nations, 1989). This discourse has been distinguishable in recent decades, especially within the multidisciplinary research field of childhood studies (Mayall, 2013).

But how are these seemingly contradictory ideas of active and passive child encountered? Furthermore, how relevant is this conflict in the context of children's digital gameplay? In general, the activity or passivity of digital playing is contingent on various factors: the type of digital game played, physical environment, social situation, the player and his/her motivation, skills, goals, and mood. In game design, this has been noticed as different games and peripherals have been developed and invented to increase activity in various ways: pointing devices that detect the movement of a player, brain-training games invented by neuroscientists, digital games that improve social skills, and so on. Since activity and passivity are dependent on various factors, we do not seek to analyze whether children's digital playing is active or not, or even how active or passive it may be. Instead, we are interested in asking how these binaries can be reflected within specific contexts and how the contradictory discourses are connected with shaping childhoods today.

\section{Starting points and objectives}

The purpose of this article is to reconsider the conceptualization of children's digital playing, especially with regard to the antithetical framework of activity and passivity. Those concepts are sometimes carelessly used in research, and it is not always even clear what the actual phenomenon is that they refer to. We looked into the theoretical literature (e.g. Kalaš, 2010; Kline et al., 2003; Stephen and Plowman, 2014) concerning children's digital playing and found out that activity and passivity are frequently related to certain antitheses, which include (1) reception and production, (2) consumption and production, (3) consumption and identity building, (4) mechanicalness and creativity, (5) antisocial and social behavior, (6) physical passivity and physical activity, (7) cognitive usefulness and cognitive futility, (8) lack of critical thinking and criticalness, and (9) entertainment and learning.

This article does not examine all of the antitheses mentioned above, but instead takes a closer look at three of them, namely, consumption and production, mechanicalness and creativity, and, finally, antisocial and social behavior. We chose these for closer analysis because they represent, from our perspective, the most recent, interesting, and in some 
cases the most persistent discursive strands. Furthermore, the chosen antitheses were strongly manifested in our empirical data. Our purpose is to explore these antitheses in relation to empirical data, instead of solely analyzing the phenomenon theoretically. We recognized that using both theoretical and empirical approaches helped to create a more rich and fertile basis for trying to understand the phenomena in question, as well as providing new insights into the field of digital gameplay.

The data used in this article are taken from Marleena Mustola's research project, in which 6-year-old children ( $n=13,10$ girls and 3 boys) from one preschool group of a Finnish day-care center played digital dress-up and makeover games. Dress-up and makeover games were chosen for the project because they are popular among children and they deal with issues related to the disciplines that Mustola uses in her work: childhood studies, art education, and cultural studies.

The research data of this qualitative case study with ethnographic qualities were collected during 3 days of intensive fieldwork with children. Before the data collection, Mustola had visited the children and discussed the research project with them. Research consents were gained from the municipality in question, the teacher, parents, and, most importantly, the children. Children were enthusiastic about participating in the study, and their excitement extended beyond gameplay sessions, for instance, by drawing different games on paper. Throughout the entire research process, standard ethical principles and guidelines of good scientific practice were followed, such as confidentiality and sensitivity toward children.

The chosen method for data collection was videotaped participant observation combined with unstructured interviews with children. In practice, Mustola and children played together on iPads, and interviews were conducted during their gameplay sessions about children's perspectives, goals, and interpretations regarding the gameplay. A total of 27 free game applications were chosen in advance for the iPad. These included, for example, Dog Dress Up, Celebrity Dentist, Toca Tailor Fairy Tales, Crazy Beard Salon, and Monster Makeover 2. The criteria for the selection of the games were that they offered the children variation of the different games displayed in the genre of dress-up and makeover games as well as gameplay possibilities for both girls and boys. The children, whether playing alone or with another child, could choose which game they wanted to try. The content and the quality of the chosen games varied. Some of them offered a lot of freedom and possibilities for the player. For instance, the player could sew different fabrics, decorate them, and produce clothing. In most of the games, however, choices were more restricted. For instance, the player could choose a dress for a character from readymade options. Not all but most of these games were also gendered, and children were often talking about "girl's games” and "boy’s games.” However, children wanted to also try games targeted at another gender than their own.

The intensive fieldwork with children resulted in 7 hours and 27 minutes of videorecorded data. The data were analyzed by means of qualitative content analysis. At the beginning of the data analysis, all of the video-recordings were transcribed. In the second phase, the videos were studied repeatedly, along with the transcripts and contextual information, while complementary notes and reflections were added to the transcripts. The next stage involved closer, in-depth analysis of the data. The unit of analysis was a meaningful episode, usually a phrase uttered during children's play. After coding the whole data set, categories were formed and then analyzed in detail. The coding of the data was abductive: the codes and categories emerged from the data, but the labeling and interpretation of those were influenced by the theoretical and conceptual frame of this study. The main categories of this study were activity and 
passivity, under which the sub-categories, for instance, production, creativity, and mechanicality, fitted.

\section{Digital play-consumption or production?}

The relationship between consumption and production is one of the key qualities ascribed to new media in general (Dovey and Kennedy, 2006: 13). Conceptually, they are often posited as opposites, as if consumption would be a passive process and production an active one (e.g. Behrenshausen, 2012; Buckingham et al., 2011; Kruikemeier et al., 2014). The current trend within media education is toward a more active use of media. The goal is to teach better media skills through active production of different types of media content, such as animations, blogs, and digital games. This has resulted in an emphasis on the positive connotations related to media production: engagement, activity, learning, and topicality. Hanna Wirman (2009) states that gameplay all in all could be seen as productivity, including activities such as cocreation between game developers and players, walkthroughs created by players, and expressive fan fiction.

Activity and passivity are also used to refer to the quality of knowledge that media users possess. David Buckingham et al. (2011) state,

It could be argued that ordinary consumers have an extensive latent (or "passive”) knowledge about media, which can somehow be activated by the experience of media production-just as language learning entails transforming the extensive knowledge we gain as listeners and readers into "active" knowledge that we can use as speakers or writers. (pp. 108-109)

Within political communication research, active Internet use includes interaction, creating, and contributing to online content, whereas passive Internet use is labeled as consuming content (e.g. reading). Player-centered approaches in game studies share a similar basic idea: the active audience member or player "does not merely consume media contents or artifacts, but also produces something-an experience, social or economic capital, new meanings - by engaging with a video game” (Behrenshausen, 2012: 875; Kruikemeier et al., 2014: 906).

The problem with this kind of dichotomy is the differentiation of receiving information and producing it. Are reading, watching, playing, and consuming media content essentially passive acts involving "passive knowledge?” We would argue that they are not, but what precisely is happening while someone is doing those things is hard to measure. There is no direct access to a person's imagination, feelings, and thinking, for instance, and it is impossible to fully know and understand what is occurring in the mind of an individual receiving media information. Conversely, the result of producing something is usually very concrete and visible as an easily assessable object.

Play activities in general are sometimes described as "unproductive," and although games include creative production (Pearce, 2009: 155), the production happening during play may seem irrelevant and non-measurable for adults. However, within early childhood education and childhood studies, the value of play is usually well recognized and not labeled as a passive act. Playing a digital game is a specific case because it cannot always be labeled as "traditional" play. Furthermore, defining digital play has proven to be a challenge (Stephen and Plowman, 2014). Sometimes playing a digital game is placed in opposition to traditional play: some studies report that the use of information and communications technology in early childhood learning "encourages children to be 
passive recipients, solitary computer game players isolated from social interactions in learning and play, deprived of movement, role playing, building things and other active experiences" (Kalaš, 2010: 24-25). Other studies imply that digital play has many of the same features as traditional play and it may increase children's cultural, social, and intellectual capital as well as any other form of play (Koivula and Mustola, 2015; Stephen and Plowman, 2014). From our perspective, digital play and traditional play share many common features, and the development or the stages of children's play becomes apparent also in the context of digital play, as our data below shows.

The following extract is an illustration of spontaneous cultural production that resulted from digital gameplay:

Haley and Sophie are playing a game Toca Tailor Fairy Tales in which the player can design and sew clothes for a female or male character (Figure 1). In the end, the player can dress the character with hats, shoes, and masks. It is Haley's turn to play. Haley has put a beard and a wolf mask onto a female character. Haley and Sophie giggle.

Researcher: Is there something funny about a beard?

Haley: A beard ...

Haley: Yes, there is ...

Giggling.

Haley: The wolf has a beard!

Sophie: And the wolf has a hat!

Haley: And the wolf has a scarf!

Researcher: Is it a real wolf?

Haley: Yes.

Laughter begins again.

Sophie: You should have made it, erm, erm, well, colored it like that, so then it would have been.

Haley: Hey. (starts to play the game)

Sophie: Put on the shoes of a wolf.

Sophie: Those.

Haley: Yeah.

Sophie: Let's dress the wolf with something funny.

Laughter.

Haley: Hey, put your eyes closed so that I can dress this with something funny. Researcher: Okay, we'll do that. Tell us when we can open our eyes.

$-$

Haley: (laughs) You may open!

Laughter. 


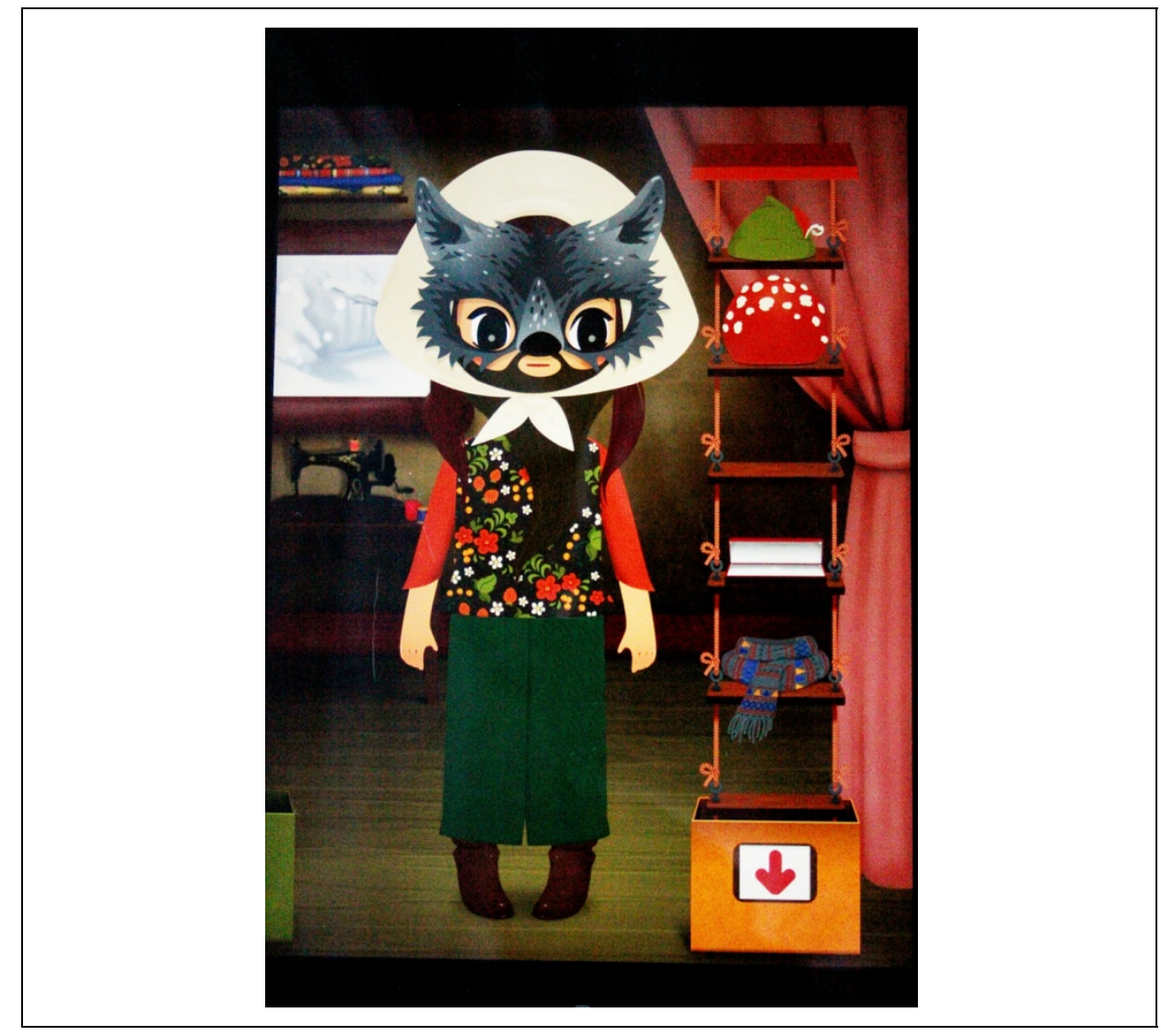

Figure 1. Haley has put a beard and a wolf mask onto a female character in Toca Tailor Fairy Tales.

Researcher: What is it?

Sophie: Eee, that!

Haley: Let's play, like, that one should guess what, what I have changed. A hat, a dress or ...

Researcher: Okay. Shall we?

Haley: Yeah.

Researcher: Eyes closed.

Sophie: I will look away, there.

Researcher: Tell us when, Haley.

Haley: What has been ... what has been, erm, taken away from this? (holds the tablet so that others cannot see it).

At the beginning of the situation, Haley and Sophie are simply playing the dress-up game and consuming its content. What happens next, though, is that the girls begin to laugh at the unconventional combination in which they have dressed the character: a wolf mask, a scarf, a hat, and a beard. Within the game they have produced something funny and inspirational. Thus, their play is illustrating production that is happening inside a digital game. Next, as Haley comes up with a new form of play, their game changes: the idea is that one player changes a piece of clothing of a character and the 
other players guess what has been changed. It is clear that Haley and Sophie produce something concrete: an interactive, rule-based game where the tablet and virtual environment of the game are used as a kind of tool. This kind of production can be obviously labeled as active, as production usually is. What about media reception, then? The next extract offers an example of the ways that seemingly passive reception and consumption of game content may be active after all:

Haley and Sophie are playing a game Dress up Princess! in which the player dresses up a princess character. It is Haley's turn to play.

Researcher: Didn't you tell me last time that those are good games because one can imagine that one is there oneself?

Haley: Yeah.

Researcher: Do you imagine while you are dressing those up that you would be the character?

Sophie: Yeah.

Haley: Yeah.

Haley: (laughs) I will still change a funny piece of clothing.

Sophie: Again. ...

Researcher: Do you imag ... what if the gir ...

Sophie: I think the ... the violet one.

Haley: Which one?

Sophie: This is not the ... not that one.

Sophie shakes her head.

Sophie: Not this, not this, not this, not this. This!

Researcher: Do you imagine only that you are those girls, or do you sometimes

imagine that you are, for instance, those dogs or ...?

Haley: I would like to be this one! Just the same!

Sophie: I would like to be ... I will show you later.

Researcher: Okay.

Sophie: And I would like to own that dog, the one I made.

Researcher: Okay. But you don't imagine being that dog?

Sophie: No. I imagine that I own that kind of dog.

Haley: Ooh!

Sophie: This is also kind of cool.

Researcher: Could one sometimes imagine being a boy?

Sophie and Haley laugh.

Haley: No one would ever want to be Steve!

Sophie: Me neither.

Haley and Sophie reveal that while they are playing, they are actively imagining their relationship to the characters, which might be labeled as digital role play or fantasy play. Some of the characters they imagine being and some of the characters they imagine owning. However, the one who imagines does not even have to be playing at the same time: she can watch someone else playing and use her imagination. If reception of media content is labeled as a passive act (see Behrenshausen, 2012: 875; Buckingham et al., 2011: 108-109; Kruikemeier et al., 2014: 906), it means that what we think, feel, and imagine while receiving content would not be active either. Could the claim of repeatedly passive reception really be supported if these kinds of active functions are mentally taking place during the reception process? The empirical data elucidate the kinds of processes children can go through while playing a game or even 
watching someone else playing. It almost seems, at least in the context of this empirical data, that media passivity could itself be a kind of active fiction.

There is also a question of consuming. Many forms of play, as well as digital games, involve consumption of commodities, and therefore, the consumer capitalism is in a sense legitimated (Langman and Lukács, 2010: 70). That is also the case with the game that Sophie and Haley end up playing, in which a player can consume commodities (e.g. choose fitting clothes and accessories for the princess character). The fact that economic exploitation is involved in children's culture cannot be denied (see Kline et al., 2003). However, as children accept products and consume them, at the same time they may reject and resist them - thus, they are subjects editing their own culture. They do not necessarily use games as they "are supposed to"; they may debate contemporary forms of capitalist culture, experiment, and act against the expectations of their age, gender, class, and race (Marsh and Millard, 2000: 21; Mustola and Thompson, 2016).

Within cultural studies, there is already a tradition of attending to the complexity of consumption as a productive process; consumption can be productive when it comes to meaning, identity, and tastes (Dovey and Kennedy, 2006: 13). For instance, the folklorist Helena Saarikoski (2009) found while examining the culture of Spice Girls fans in Finland that their consumption of fan products appeared to be a way to build an identity. The process of building an identity is an active process, too. There does not seem to be very firm arguments in support of the idea of reception and consumption being passive processes. The discourse on passivity when receiving and consuming media content is probably an endeavor to emphasize that the activity is more passive than something else (for instance, receiving media content is more passive than producing it). It is not clear, however, how different kinds of actions can be hierarchically organized in a plausible way. Is the act of taking a photograph (media production) really more active than the act of imagining oneself as a media character while consuming media content, and if so, in terms of what?

\section{Digital play-mechanical or creative?}

As Haley and Sophie show, there are imaginative spaces that children create while playing digital games. Imagination, which is individual and communal, messy and contradictory, is linked to creativity (Mustola and Thompson, 2016). There are many games that allow and encourage the player to create, for instance, digital environments, narratives, and personalized characters. Nonetheless, computer games are at the same time mechanical, based on algorithmic rule sets (Dovey, 2006: 136), and governed by a specified set of rules and parameters (Grimes and Feenberg, 2012: 32). There are also games that focus more on executing than on creating. The process of playing these kinds of games is sometimes defined as more passive, mechanical, or even mindless. One stereotype related to gaming is that it is about "mindless computer games played by teenage boys" (Egenfeldt-Nielsen et al., 2011: 7). Judd Ethan Ruggill and Ken McAllister (2011: 6) argue that the computer game medium is "enigmatic despite seeming mechanical and predictable.” Mechanicality can therefore refer to game playing that is repetitive and unsurprising. It also suggests that the role of game player is not very central. This is what Janet Murray (2011) notices when considering the agency of a player as an opposition for powerlessness. Murray (2011: 24) points out that in a well-designed game environment, agency and immersion "reinforce one another through the active creation of belief."

The game researcher Celia Pearce (2009: 155-156) identifies different ways in which play can be productive: players invent new game activities, social rituals, and 
cultural practices, and they create new game environments. When Henrik SchoenauFog (2014: 393-394) examined player engagement on the grounds of an online survey, he found out that there are 10 activities across all types of games that serve as major causes for wanting to continue playing. One of these is creating something (e.g. structures and buildings in games such as Minecraft) (Schoenau-Fog, 2014: 394). The definition of creativity as fulfilling some kind of physical end result is problematic, as it does not include imaginative spaces that the researcher cannot necessarily perceive when observing the gameplay situation. If creativity is strongly linked to productivity, as it is with the concepts and definitions that Pearce uses, it disregards the element of imagination.

Another way of regarding creativity is to understand it as a form of problemsolving: a person produces a solution that is novel (i.e. original, unexpected) and appropriate. According to Ronald Beghetto and James Kaufman (2007: 73), the nature of creativity of young children is typically so-called "mini-creativity," defined as "the novel and personally meaningful interpretation of experiences, actions, and events." It is enough that the idea is new and meaningful, internally for the child or interpersonally also for the peers in the group. This kind of everyday "mini-creativity" helps to elaborate a broader conception of creativity (Beghetto and Kaufman, 2007: 75). The extract below demonstrates how digital games can contribute to imagination: a person's perception of what is and what may be:

Zoe and Wyatt are playing a game Celebrity Dentist in which the player can wash, fix, decorate, and color the teeth of a character (Figure 2). The player can color the teeth with many different colors, including green, purple, and pink. It is Wyatt's turn to play.

Zoe: Why does it have golden teeth and holes and gums and everything ...!?!

Researcher: Why do some people have?

Zoe: I don't know.

Researcher: What kind of teeth would be the coolest, Zoe? What do you think?

Zoe: Er ... the kind of ordinary (points at her own teeth).

Researcher: Um.

Zoe: Just like yours.

Researcher: And yours. Would it be cool if one had pink teeth?

Zoe seems terrified.

Zoe: No.

Zoe: Although, I would like it.

Researcher: (to Wyatt) You can get a tooth from there to replace it.

Zoe: Push it ...

Zoe: Now you have to, there ... (plays Wyatt's game)

Zoe: Those holes are fixed, those holes are fixed.

Researcher: There one can color those teeth, and put some decorations on them. 


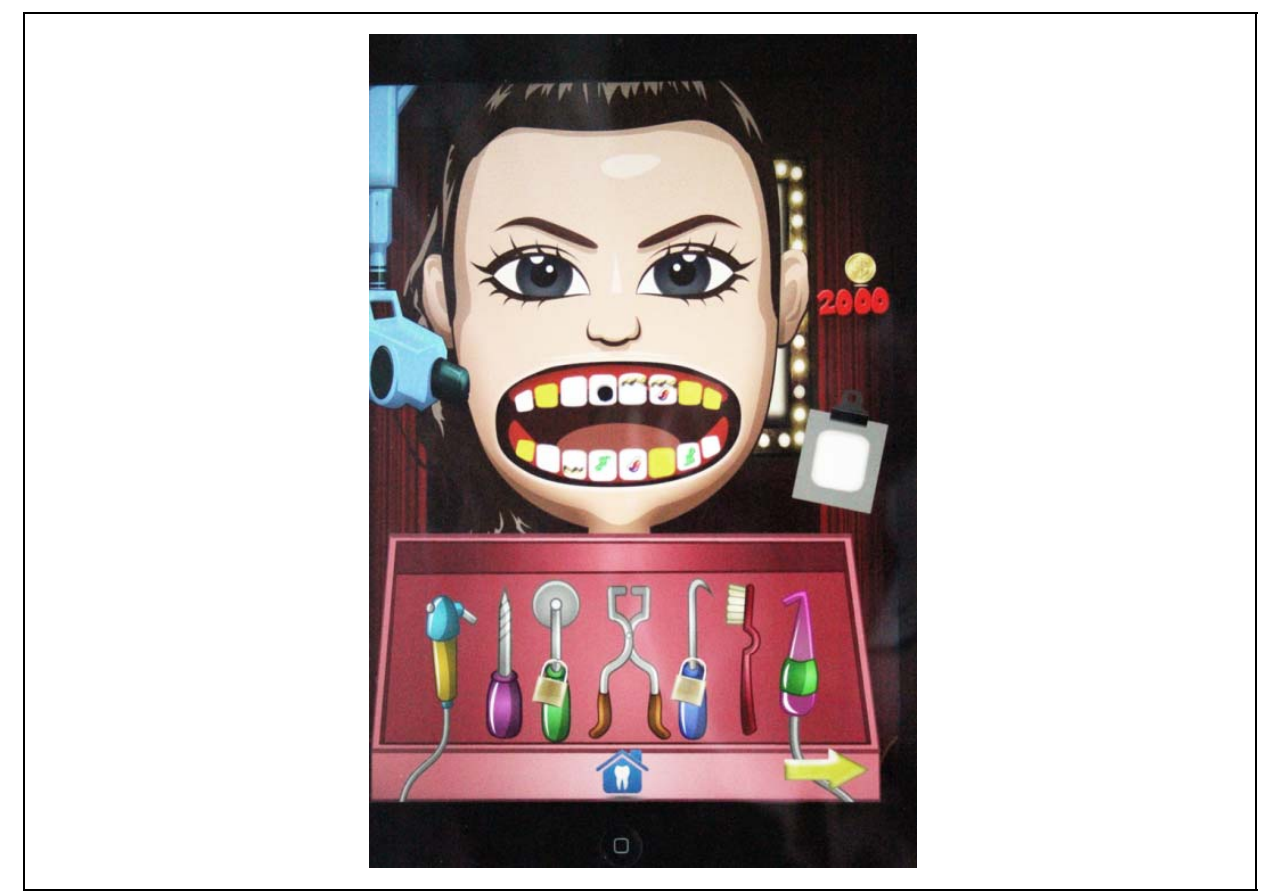

Figure 2. Wyatt fixes the teeth in Celebrity Dentist.

Zoe: Color the teeth!

Zoe: (whispers quietly to Wyatt) Put the pink ones.

Before seeing the coloring options for the character's teeth, Zoe thinks that ordinary teeth are "the coolest." She seems to be terrified of the researcher's suggestion of pink teeth. Probably she hadn't even thought about the option of coloring teeth with unusual hues. After she thinks about it and sees what kind of coloring options are offered by the game, she starts to get excited about the idea of pink teeth and asks Wyatt to use that specific color for the character's teeth. The digital imagery and fictional ideas that digital games offer have to do with what we think about the world, ourselves, and all that does not yet exist in the real world. The cultural products shape our imagination and affect what kind of imagery and ideas we create. Considering carnivalization in digital games, the sociologists Lauren Langman and András Lukács (2010: 71) emphasize that it "provides times and spaces where alienation and rationality can be overcome, where people can assert humanity that refuses to be rationalized and dehumanized and find creative fulfilment in play."

All in all, digital gameplay environments as a whole can be seen as co-created worlds constituted of the imaginations of the game designer and the player. Some game environments, which Celia Pearce calls "fixed synthetic worlds," are defined primarily by game designers who have control over the narratives, game mechanics, world rules, and architectural design. Other environments can be called open-ended and co-created: they allow the player to produce content and to customize avatars and environments. However, these co-created worlds are also limited by the imagination of the game designers, and therefore, fixed synthetic worlds should not be regarded as less creative. Within these fixed synthetic worlds, "the ways in which players appropriate and subvert the environment to their own ends can be extremely creative” (Pearce, 2009: 
31-35). Also, when considering creativity and mechanicalness in digital gameplay, the focus should not be on gameplay situations alone. It is worth regarding what happens after the games are played. For instance, Kathryn Gold Hadley and Sandi Kaweka Nenga (2004: 532) discovered that children "creatively appropriated media messages to address their own values and concerns within the context of their peer culture." Also here, the children who participated in this study continued voluntarily and actively to work on the themes of the digital games they played. They developed their own digital games and drew them.

The way in which digital games are understood as tools of education varies. Some views emphasize the more mechanical aspect of the games as a literacy learning tool, while some concentrate on creative opportunities. In England, for instance, it is widely understood that games are an important tool for acquiring basic skills that can be trained through memorization and recall. In turn, game-based learning in Scotland is associated with the creativity and design of games, which are understood as central competences for a new generation of learners (Meyer et al., 2011: 80-81). Both views, one emphasizing creativity and another mechanical repetition, acknowledge the potential of digital games as learning tools, and there is not a value judgment of creative, learner-centered, or active being better in this case. When it comes to learning, there is a need for both mechanical and creative ways to acquire knowledge, depending, for instance, on the desired learning outcomes and educational policies (see Meyer et al., 2011: 80-82).

\section{Digital play-antisocial or social?}

Traditionally, video games have been associated with isolation and antisocial behavior. However, nowadays this perception can be regarded as outmoded since many games include some kind of social component. Often games are played together in the same physical space. There is also a category of "social games," meaning a game played on social networks. Especially in multiplayer games, the desire to manage social situations is essential, and every game action is also framed by consideration of the game as a social event and construction of player's social status (Costikyan, 2013: 49; Jessen, 2011: 165).

Interaction appears to be a key factor when considering if the process of gameplay is social ("active") or antisocial ("passive"). However, interaction does not only happen between human beings but also between a player and technical equipment, which makes it harder to define if there is interaction and what its quality is. There is a definite dichotomy between a virtual, artificial environment and a physical, real-world environment (De Almeida et al., 2015: 2), as well as between human-computer interaction and human-human interaction. With advanced technology, however, the question is more complicated than that. How should interaction between real humans via digital technology be labeled? And what happens when machines are developing and becoming more human-like? Interactivity of digital games has been also represented as "a dramatic emancipatory improvement over traditional one-way mass media” (Kline et al., 2003: 14). However, Janet Murray (2011: 12) argues that interactivity cannot be a design goal in itself, because there can exist both good and bad interaction between computers and humans. Instead, Murray (2011: 12-13, 101-102) emphasizes the ability of machine to create a satisfying experience of agency for the interactor. The next example illustrates human-computer interaction, as 6-year-old children are trying out a new kind of game: 
Zoe and Wyatt are playing a game Talking Anya in which the player can dress up a girl character. The player can also talk to the character and the character

repeats it. Sometimes the character speaks its own stories and dances. The player can move it, too.

Researcher: Hmm, one can also record one's own speech and it will repeat it.

Zoe: What?

Researcher: Those are locked up.

iPad: (high-pitched) Record one's own speech and it will repeat it.

Researcher: You can't take those locked ones, but you can take anything else.

Zoe shows hush-sign with her hands. Researcher nods.

Wyatt: Why does that always repeat what is said? Why wouldn't it be ... huh?

iPad: Wouldn't it be ... huh?

Everyone laughs.

iPad: I love you!

Wyatt: Huh? What was that?

Wyatt: Well then, it may also ...

iPad starts to play some dance music.

Wyatt: (as if disapproving) Oh dear.

There are already interactive toys with significantly more advanced artificial intelligence (AI) than the game application used by Zoe and Wyatt in the extract. Interaction with the digital girl character in this case is still quite clumsy because the character does not specifically respond to players' initiatives. She only repeats what is said to her or speaks something that is not responsive to the players' discussions. Nevertheless, interaction exists. Zoe silences the researcher because she wants to hear what the girl character is saying. Wyatt reacts to the character's comments on several occasions. Both children and the researcher laugh when the girl character mimics what Wyatt says. This could also be the result in the case of a child mimicking another child: it is usually about engaging in antics, whose purpose is to make everybody laugh or to annoy them.

Researchers have struggled with definitions of passive and active play and their relation to interaction. Even if there is no direct (visible or audible) interaction between the player and another human or the player and a machine, the gameplay process should not be perceived too readily as being antisocial. The social reality is still present, for instance, via social objects. Social ontology studies objects that exist "only inasmuch as people believe in them, such as the money value, the State Law, the game rules, or the fictive identities” (Mosca, 2014: 611). It is clear that digital game environments include a lot of social objects, such as game rules and fictive identities. Games rules can also enable the transgression of many ordinary social conventions such as general helpfulness (Juul, 2013: 56).

\section{Discussion}

Activity and passivity are complex concepts, at least when used in the context of children's digital gameplay. First, the discourses in which they are used are diverse, and they can refer to several different phenomena. Second, it is usually not about a question of either/or. In virtually every gameplay situation, there are both "passive" 
and "active" elements involved. Third, activity and passivity often seem to be used as value judgments. Active engagement is almost inevitably a positive thing, while passivity has a negative connotation. This is a commonly accepted valuation in Western societies; being an active citizen and an active being in different sectors of life is highly appreciated in our culture. For these reasons, use of the definitions "active" and "passive" within a theoretical discussion of digital games should be carefully considered; a naive or careless use of these concepts does not really advance the multidisciplinary discussion regarding either digital games or childhood.

What we found out when examining the concepts "active" and "passive" in relation to empirical data is that these concepts have actual and various affordances when examining children's digital gameplay and perhaps also other media use. With these concepts it is possible to describe in detail the diversity and complexity of a gameplay act. However, for the successful use of these concepts, they need to be thoroughly contextualized. We claim that by discussing the context and referent of activity and passivity it is possible to overcome the unnecessary polarization of the discourses on children's digital game culture.

The question of passivity and activity ultimately has its roots in ontology and philosophy: how do we perceive an individual's autonomy, intentionality, and agency (see Bratman, 2007)? The variety of ways of understanding these issues can be seen in discussions on children and digital gameplay. Furthermore, if the individual in question is a child, the situation is even more complicated since childhood as a social construction (see Alanen, 2015) varies within different cultures, different contexts, and different disciplines. Our article points out how the current, digital childhoods are socially constructed within certain contexts.

Consequently, it is critical who defines the passivity and activity in question. For the children participating in this project digital gameplay turned out to be stimulating and enticing. Claims about media harming children, for instance, have focused not on children's but adults' concerns and assumptions that children passively and uncritically assimilate images and messages (Hadley and Nenga, 2004: 515). Constructions of a passive child as a digital game player have consequences: if "passive" discourse and moral panic prevail, there will be more regulations and less use of digital games for education, thereby inhibiting the developmentally positive and beneficial effects of gameplay for children. As Sonia Livingstone et al. (2015: 4) highlight, we should consider how children's basic rights are being enhanced or undermined in the digital age.

To be sure, these discourses are not free of politics. As Neil Selwyn (2003: 374) writes, "the notion of the child computer user, is to a large degree, merely a means of persuasion and promotion on the part of key commercial and political guiding interests of the information age." As it has been apparent in the debates on children's Internet use, research on supposed dangers has attracted more public attention and the academy has tried to point out that the stress on dangers is biasing the policy agenda away from a constructive exploration of the subject. Critical analyses of the debates themselves and the terms used in those are still needed (Livingstone, 2003: 150-151). This is also the case when considering the debate on activity and passivity of digital gameplay.

The question of activity and passivity of children playing digital games defines not only the agency of children but also the agency of technical devices. The network that humans create in the way they inhabit this planet is also a material one, and its agency exceeds the political, social, and biological human realms (Ferrando, 2013: 32). The French philosopher, anthropologist, and sociologist Bruno Latour (2005: 70) points out in the context of advancing Actor network theory that it is necessary to make objects participants in the course of action. For Latour, non-humans-such as a kettle or 
hammer-are worth giving a thought to, a social thought. He notes that the reason that social scientists abandoned things and objects to the scientists and engineers has nothing to do with theory, but with territories of disciplines (Latour, 2005: 73, 83). If we concentrate on reasoning the concepts of activity and passivity, uncontextualized and carelessly used in the context of children's digital playing, we find both to be absurd in a theoretical sense and also too abstract when examined in terms of just one discipline. Especially in the future, as technology evolves further, there will be a need to essentially understand the activities of both (child) players and digital games, and how these two encounter one another.

\section{Funding}

The author(s) received no financial support for the research, authorship, and/or publication of this article.

\section{References}

Alanen L (2015) Are we all constructionists now? Childhood 22(2): 149-153.

Beghetto RA and Kaufman JC (2007) Toward a broader conception of creativity: a case for "mini-c" creativity. Psychology of Aesthetics, Creativity, and the Arts 1(2): 73-79.

Behrenshausen BG (2012) The active audience, again: player-centric game studies and the problem of binarism. New Media \& Society 15(6): 872-889.

Blum C and Parette HP (2015) Universal design for learning and technology in the early childhood classroom. In: Heider KL and Jalongo MR (eds) Young Children and Families in the Information Age: Applications of Technology in Early Childhood. Dordrecht: Springer Netherlands, pp. 165-182.

Bratman M (2007) Structures of Agency: Essays. Oxford: OUP Premium.

Buckingham D and Sefton-Green J (2003) Gotta catch 'em all: structure, agency and pedagogy in children's media culture. Media, Culture \& Society 25(3): 379-399.

Buckingham D, Willett R and Pini M (2011) Home Truths? Video Production and Domestic Life. Ann Arbor, MI: University of Michigan.

Costikyan G (2013) Uncertainty in Games. Cambridge, MA; London: The MIT Press.

De Almeida AN, Delicado A, De Almeida Alves N, et al. (2015) Internet, children and space: revisiting generational attributes and boundaries. New Media \& Society 17(9): 1436-1453.

Dovey J (2006) How do you play? Identity, technology and ludic culture. Digital Creativity 17(3): 135-139.

Dovey J and Kennedy HW (2006) Games Cultures: Computer Games as New Media. Berkshire: Open University Press .

Egenfeldt-Nielsen S, Meyer B and Sørensen BH (2011) Preface. In: Egenfeldt-Nielsen S, Meyer B and Sørensen BH (eds) Serious Games in Education: A Global Perspective. Aarhus; Copenhagen: Aarhus University Press, pp. 7-18.

Ferrando F (2013) Posthumanism, transhumanism, antihumanism, metahumanism, and new materialisms: differences and relations. Existenz: An International Journal in Philosophy, Religion, Politics, and the Arts 8(2): 26-32.

Grimes M and Feenberg A (2012) Rationalizing play: a critical theory of digital gaming. In: Feenberg A and Friesen N (eds) (Re)Inventing the Internet: Critical Case Studies. Rotterdam: Sense Publishers, pp. 21-41.

Hadley KG and Nenga SK (2004) From Snow White to Digimon: using popular media to confront Confucian values in Taiwanese peer cultures. Childhood 11(4): 515-536.

Jenkins H (2006) The Wow Climax: Tracing the Emotional Impact of Popular Culture. New York: New York University Press.

Jessen C (2011) Learning games and the disruptive effects of play. In: Egenfeldt-Nielsen S, Meyer B and Sørensen BH (eds) Serious Games in Education: A Global Perspective. Aarhus; Copenhagen: Aarhus University Press, pp. 153-169. 
Juul J (2013) Art of Failure: An Essay on the Pain of Playing Video Games. Cambridge, MA; London: The MIT Press.

Kalaš I (2010) Recognizing the Potential of ICT in Early Childhood Education. Moscow: UNESCO Institute for Information Technologies in Education.

Kline S, Dyer-Witheford N and De Peuter G (2003) Digital Play: The Interaction of Technology, Culture, and Marketing. Montreal \& Kingston; London; Ithaca: McGill-Queen's University Press.

Koivula M and Mustola M (2015) Leikisti pelissä—pohdintaa lasten digitaalisen pelaamisen ja leikin suhteesta [Playfully in game-considering the relationship between digital game play and traditional play]. In: Koskimaa R, Suominen J, Mäyrä F, et al. (eds) Pelitutkimuksen vuosikirja 2015 [The Annual of Game Studies 2015]. Tampere: Tampereen yliopisto, pp. 39-53.

Kruikemeier S, Van Noort G, Vliegenthart R, et al. (2014) Unraveling the effects of active and passive forms of political internet use: does it affect citizens' political involvement? New Media \& Society 16(6): 903-920.

Langman L and Lukács A (2010) Capitalism, contradiction, and the carnivalesque: alienated labor vs. ludic play. In: Wright JT, Ebrick DG and Lukács A (eds) Utopic Dreams and Apocalyptic Fantasies: Critical Approaches to Researching Video Game Play. Lanham, MD; Boulder, CO; New York; Toronto, ON, Canada; Plymouth: Lexington Books, pp. 59-72.

Latour B (2005) Reassembling the Social: An Introduction to Actor-Network-Theory. Oxford: Oxford University Press.

Livingstone S (2003) Children's use of the internet: reflections of the emerging research agenda. New Media \& Society 5(2): 147-166.

Livingstone S, Byrne J and Bulger M (2015) Researching children's rights globally in the digital age (Report of a seminar held on 12-14 February 2015 London School of Economics and Political Science). Available at: http://www.lse.ac.uk/media@lse/research/ResearchProjects/Researching-Childrens-Rights/pdf/Researching-childrens-rights-globally-in-thedigital-age-260515-withphotos.pdf (accessed 13 December 2015).

McClure M and Sweeny RW (2015) Participatory youth culture: young children as media and MOC makers in a post-millennial mode. In: Heider KL and Jalongo MR (eds) Young Children and Families in the Information Age: Applications of Technology in Early Childhood. Dordrecht: Springer Netherlands, pp. 245-254.

Marsh J and Millard E (2000) Literacy and Popular Culture: Using Children's Culture in the Classroom. London: SAGE.

Marsh J and Richards C (2013) Play, media and children's playground cultures. In: Willett R, Richards C, Marsh J, et al. (eds) Children, Media and Digital Playground Cultures: Ethnographic Studies of School Playtimes. Basingstoke: Palgrave Macmillan, 1-20.

Mayall B (2013) A History of the Sociology of Childhood. London: Institute of Educational Press.

Meyer B, Sørensen BH, Hanghøj T, et al. (2011) Making connections_-global and local issues in researching the policy of serious games in education. In: Egenfeldt-Nielsen S, Meyer B and Sørensen BH (eds) Serious Games in Education: A Global Perspective. Aarhus; Copenhagen: Aarhus University Press, pp. 59-83.

Mills R (2002) Perspectives of childhood. In: Mills J and Mills RW (eds) Childhood Studies: A Reader in Perspectives of Childhood. London; New York: Routledge, pp. 7-38.

Mosca I (2014) Social ontology of digital games. In: Angelides MC and Agius H (eds) Handbook of Digital Games. Hoboken, NJ: John Wiley \& Sons, pp. 607-644.

Murray JH (2011) Inventing the Medium: Principles of Interaction Design as a Cultural Practice. Cambridge, MA; London: The MIT Press.

Mustola M and Thompson CM (2016) Children, digital games, and the question of global imagination, Submitted.

Pearce C (2009) Communities of Play: Emergent Cultures in Multiplayer Games and Virtual Worlds. Cambridge, MA; London: The MIT Press.

Postman N (1994 [1982]) The Disappearance of Childhood. New York: Vintage Books.

Rhodes M (2002) Uncovering the history of childhood. In: Mills J and Mills RW (eds) Childhood Studies: A Reader in Perspectives of Childhood. London; New York: Routledge, pp. 163-180. 
Ross K and Nightingale V (2003) Media and Audiences: New Perspectives. Berkshire: Open University Press.

Ruggill JE and McAllister KS (2011) Gaming Matters: Art, Science, Magic, and the Computer Game Medium. Tuscaloosa, AL: The University of Alabama Press.

Saarikoski H (2009) Nuoren naisellisuuden koreografioita. Spice Girlsin fanit tyttöyden tekijöinä [The Choreographies of Young Femininity: the Fans of Spice Girls as Composers of Girlhood]. Helsinki: Suomalaisen Kirjallisuuden Seura.

Schoenau-Fog H (2014) At the core of player experience: continuation desire in digital games. In: Angelides MC and Agius H (eds) Handbook of Digital Games. Hoboken, NJ: John Wiley \& Sons, pp. 388-410.

Selwyn N (2003) "Doing IT for the kids": re-examining children, computers and the “information society.” Media, Culture \& Society 25(3): 351-378.

Shaw P and Tan Y (2015) Constructing digital childhoods in Taiwanese children's newspapers. New Media \& Society 17(11): 1867-1885.

Stephen C and Plowman L (2014) Digital play. In: Brooker L, Blaise M and Edwards S (eds) The Sage Handbook of Play and Learning in Early Childhood Education. Los Angeles; London: SAGE, pp. 330-341.

United Nations (1989) United Nations Convention on the Rights of the Child. Geneva: United Nations.

Wirman H (2009) On productivity and game fandom. Transformative Works and Cultures 3. Available at: http://dx.doi.org/10.3983/twc.2009.0145 (accessed 12 December 2015).

\section{Author biographies}

Marleena Mustola, PhD (art and culture studies), is university teacher in Early Childhood Education at the University of Jyväskylä. Her research interests include the social study of childhood, children's interaction with and views on digital games, children's contemporary culture, art and media education, and posthuman philosophy.

Merja Koivula, PhD (educational sciences), is post-doctoral researcher in Early Childhood Education at the University of Jyväskylä. Her current research interests include the use of tablet computers in preschool from the perspective of children and teachers, children's digital play, collaborative learning in the early childhood education settings, and the development of young children's socio-emotional competence.

Leena Turja, $\mathrm{PhD}$ (educational sciences), is senior lecturer in Early Childhood Education (ECE) at the University of Jyväskylä. Her research interests concern children's participation and voice in research and practice of ECE, children's socio-emotional learning, science and technology education integrated with arts and math (STEAM) in early years, and leadership of ECE services.

Marja-Leena Laakso, PhD (psychology), is Professor in Early Childhood Education, especially Child and Developmental Psychology, at the University of Jyväskylä. Her research interests include intervention studies on supporting young children's socio-emotional development, early communication and language development, hearing children in the contexts of educational and psychological services, and use of digital technologies in the early years. Professor Laakso has been one of the main developers of the "Emotion Detectives" digital game designed for supporting children's acquisition of emotional knowledge skills. 